\title{
ABSTRACT \\ Comparison of Blood Group Based on Bleeding Manifestation in Pediatric Dengue Cases
}

Amrina Rosyada, Sulistiawati and Dominicus Husada

Background: Dengue clinical manifestation presents mostly due to the impairment of blood homeostasis that causes the presence of bleeding manifestation. Previous studies mentioned that blood group $\mathrm{O}$ have a higher bleeding risk than non-O blood groups. The objective of this study was to know the comparison of blood group based on bleeding manifestation in pediatric dengue cases.

Methods: This cross-sectional with consevutive sampling study involved 86 dengue pediatric patients in Instalasi Rawat Inap Anak RSUD Dr. Soetomo Surabaya during March 2016-September 2016. The sample numbers that fulfilled the inclusive criteria were 52 patients. The others were excluded because 25 subjects had incomplete bleeding manifestation data, 6 subjects had incomplete blood group data, and 3 subjects were excluded due to previous blood disease history. The data collected using medical records and analyzed using chi-square test with p-value (p) $<0.05$ and confidence interval (CI) $95 \%$.

Results: There were no significant difference between $\mathrm{ABO}$ blood group system based on bleeding manifestation ( $\mathrm{p}=0.579)$ and no significant difference between blood group $\mathrm{O}$ and Non-O based on bleeding manifestation ( $\mathrm{p}=0.600)$.

Conclusion: There were no significant difference between blood group based on bleeding manifestation, thus the physician should always be aware of the presence of bleeding in dengue cases. Further research is needed to define the risk factor of bleeding presence in dengue cases.

Keywords: blood group, pediatric, dengue, bleeding manifestation 